\title{
DOES B-MODE COMMON CAROTID ARTERY INTIMA-MEDIA THICKNESS DIFFER FROM M-MODE?
}

\author{
Luc M. Van Bortel, ${ }^{*}$ Floris H. Vanmolkot, $*$ \\ Janneke J. van der Heidden-Spek, * Marsel Bregu,* Jan A. Staessen ${ }^{\S}$ and \\ ARNOLd P. HoEKs ${ }^{\dagger}$ \\ Departments of *Pharmacology and ${ }^{\dagger}$ Biophysics, Maastricht University, Cardiovascular Research Institute \\ Maastricht (CARIM), Maastricht, The Netherlands; ${ }^{*}$ Heymans Institute of Pharmacology, Ghent University, Ghent, \\ Belgium; and ${ }^{\S}$ Hypertension Unit, University of Leuven, Leuven, Belgium \\ (Received 23 April 2001; in final form 20 July 2001)
}

\begin{abstract}
An increased intima-media thickness of the common carotid artery is thought to be an early sign of atherosclerosis. Both B- and M-mode ultrasonographic techniques are used to measure the intima-media thickness of the common carotid artery (B-IMT and M-IMT, respectively). The present study compares intima-media thickness of the common carotid artery measured with the two techniques. Intima-media thickness was measured in a random population sample of 250 subjects. Comparison was made by mean and $95 \%$ confidence intervals of differences between B-IMT and M-IMT, by linear regression analysis, and by intraclass and concordance correlation coefficients. M-IMT was $+0.011 \pm 0.091 \mathrm{~mm}(95 \%$ confidence intervals: -0.167 to $+0.188 \mathrm{~mm}$ ) larger than B-IMT, which was $0.661 \pm 0.136 \mathrm{~mm}$ (range: 0.380 to $1.120 \mathrm{~mm}$ ). Intraclass and concordance correlation coefficients were 0.802 and 0.801 , respectively. In conclusion, acceptable agreement exists between the two methods and there was no important systematic difference between B-IMT and M-IMT. (E-mail: luc.vanbortel@rug.ac.be) (C) 2001 World Federation for Ultrasound in Medicine \& Biology.
\end{abstract}

Key Words: Intima-media thickness, B-mode, M-mode, Arterial wall, Common carotid artery, Atherosclerosis, Diagnostic imaging.

\section{INTRODUCTION}

Intimal thickening at the carotid artery has been suggested as an early stage of atherosclerotic disease (Stary et al. 1992). In vivo, intimal thickening cannot be measured noninvasively. Intima-media thickness (IMT) can be measured with ultrasound (US). An increased IMT can be due to intimal and/or muscular thickening (Grobbee and Bots 1994). At the common carotid artery (CCA), an increased IMT has been found associated with clinically manifest disease (Burke et al. 1995; Salonen and Salonen 1991). As a consequence, at the site of the CCA, IMT is considered mainly due to intimal thickening (Grobbee and Bots 1994), and has been proposed as a surrogate for intimal thickening at this arterial site.

The ultrasonographic measurements of carotid artery IMT have acceptable accuracy (Girerd et al. 1994; Hoeks et al. 1997; Persson et al. 1994; Pignoli et al.

Address correspondence to: Prof. Dr. Luc Van Bortel, Heymans Institute of Pharmacology, Ghent University, De Pintelaan 185, B-9000 Ghent, Belgium. E-mail: luc.vanbortel@rug.ac.be
1986; Wendelhag et al. 1991; Wong et al. 1993) and are reproducible (Mountauban van Swijndregt et al. 1999; Smilde et al. 1997; Stensland-Bugge et al. 1997; Willekes et al. 1999), especially when applied in large multinational clinical trials (Kanters et al. 1998; Tang et al. 2000). Its noninvasive character and easy applicability make ultrasonography a powerful tool for assessment of early atherosclerotic vessel wall changes, even in asymptomatic patients where the artery lumen is not yet obstructed (Crouse and Thompson 1993; Probstfield et al. 1995). IMT can be measured in different segments of the carotid artery, such as the common carotid artery, bulbus, and internal carotid artery, but reproducibility is higher in the common carotid artery (CCA) segment (Mountauban van Swijndregt et al. 1999).

Different US techniques have been used to measure the IMT of the CCA. One technique, using high-resolution B-mode images, was proposed by Bond and Ball (1986) and Pignoli et al. (1986) and further elaborated by Wendelhag et al. (1991). In this 2-D US image of the CCA, the anterior wall, the lumen and the posterior wall 
Table 1. Subjects' characteristics

\begin{tabular}{lc} 
Demographic data $(n=250)$ & \\
\hline Male/female & $118 / 132$ \\
Age (years) & $50 \pm 13$ \\
BMI $\left(\mathrm{kg} / \mathrm{m}^{2}\right)$ & $26 \pm 4$ \\
Smokers & 85 \\
SBP $(\mathrm{mmHg})$ & $120 \pm 14$ \\
DBP $(\mathrm{mmHg})$ & $72 \pm 9$ \\
\hline
\end{tabular}

$\mathrm{BMI}=$ body mass index; $\mathrm{SBP}=$ systolic blood pressure; $\mathrm{DBP}=$ diastolic blood pressure; data are number or mean \pm SD.

can be distinguished. Both walls present 1. an echogenic, 2. an echo-poor, and 3. an echogenic zone. IMT of the far wall is measured, whereas that of the near wall is not considered because measurements of the line pattern at the near wall have to be performed at the trailing edges of the US pulse and are, therefore, not representative of IMT. As a result, these measurements depend on gain settings and resolution characteristics of the US device, and represent only $80 \%$ of the histologic thickness (Wong et al. 1993). In the far wall, the interface between lumen and intima gives rise to the leading edge of the first echogenic zone. The leading edge of the second echogenic zone in this wall very likely corresponds to the media-adventitia interface (Pignoli et al. 1986). The distance between these two leading edges is taken as IMT (Pignoli et al. 1986), and truly reflects the anatomical IMT (Pignoli et al. 1986; Wendelhag et al. 1991).

Another technique, using M-mode images, has been proposed by Roman et al. (1992). Two-dimensionally guided M-mode tracings of the common carotid artery are performed and stored for off-line analysis. Following calibration for depth and time, the end-diastolic wall thickness of the far wall is measured. In contrast to B-mode IMT, which represents the average IMT of an arterial segment, M-mode IMT is the IMT at a discrete arterial position.

Because studies comparing the two techniques are lacking, it is not clear if these two techniques produce similar results. The present study compares the results of IMT of the CCA measured with these two techniques in 250 subjects from a random population sample.

\section{MATERIALS AND METHODS}

\section{Subjects}

The subjects' characteristics are presented in Table 1. Subjects were part of a random population sample (van der Heijden-Spek et al. 2000). They were from 27 to 82 years old; the majority were older than 50 years. Their body mass index (BMI) ranged from 16 to $45 \mathrm{~kg} / \mathrm{m}^{2}$. The study was approved by the local ethics committee and written informed consent was obtained from all subjects.

\section{Carotid ultrasonography}

Ultrasonography of the right CCA was performed in all subjects, using a conventional echo-imaging system (Ultramark V, ATL, Bothel, WA) equipped with a 7.5$\mathrm{MHz}$ linear-array transducer. After 15 min of supine rest, subjects were examined with the head turned $45^{\circ}$ opposite to the site being scanned. Registrations in B-mode and M-mode of the far wall were made consecutively at $1 \mathrm{~cm}$ proximal to the bulb, without displacing the transducer. An optimal 2-D image in B-mode was obtained and images were continuously recorded on videotape. To obtain M-mode images, an M-line perpendicular to the vessel was selected in an optimal B-mode image and the US system was switched to M-mode. M-mode images were also continuously recorded on videotape. A simultaneously recorded electrocardiogram was used to maintain a constant time relationship between the IMT measurements and the cardiac cycle. All measurements were performed by one investigator.

\section{Image analysis}

Evaluable frozen end-diastolic B-mode images on the videotape were digitized, stored on disc and analyzed off-line using a computerized image-analyzing system. This procedure has been described in detail by Wendelhag et al. (1991). Briefly, with a cursor the interfaces of the far wall of the CCA were traced manually over a length of at least $6 \mathrm{~mm}$. IMT is calculated automatically by the computer by dividing the area of the intima-media complex by the length of the arterial segment. Six Bmode images were analyzed and the mean of four registrations after exclusion of the highest and lowest value was calculated.

Suitable frozen end-diastolic M-mode images on the videotape were analyzed off-line using a computerized system with an image-shearing device that was built in our institute, according to the description of Intaglietta and Tompkins (1973). Following calibration for depth, the end-diastolic IMT was measured. Eight M-mode images were analyzed and the mean of six registrations after exclusion of the highest and lowest value was obtained. B-mode and M-mode images were analysed by one reader. In our hands, the intrasession and intersession coefficients of variation of these image analyses were $2.9 \%$ and $5.3 \%$ for B-mode IMT (B-IMT) and $1.4 \%$ and $5.4 \%$ for M-mode IMT (M-IMT), respectively.

\section{Statistical analysis}

Data are presented as mean \pm SD. Comparison of the two techniques was made by: 1. mean and 95\% confidence intervals (CI) of differences between B-IMT and M-IMT according to Bland and Altman (1986); 2. intraclass (ICC) and concordance (CCC) correlation coefficients according to Deyo et al. (1991); and 3. linear 


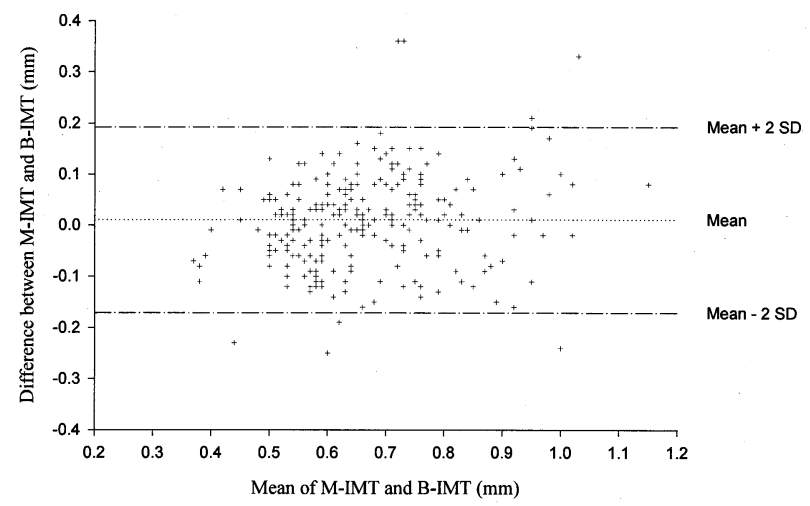

Fig. 1. Agreement between intima-media thickness measured with M-mode and with B-mode. Bland and Altman scatterplot $(n=250)$; M-IMT and B-IMT = intima-media thickness measured with M-mode and with B-mode, respectively. Lines are drawn for the mean difference and 2 SD around the mean difference.

regression analysis and Pearson (r) correlation coefficient. ICC reflects 1 . overall correlation; 2 . systematic difference; and 3 . agreement with the $45^{\circ}$ line of identity. The concordance correlation coefficient $(\mathrm{CCC})$ reflects the agreement between the observed data and a $45^{\circ}$ line of identity (Lin 1989).

\section{RESULTS}

B-IMT and M-IMT in the study population averaged $0.661 \pm 0.136 \mathrm{~mm}$ (range: 0.380 to $1.120 \mathrm{~mm}$ ) and $0.672 \pm 0.152 \mathrm{~mm}$ (range: 0.328 to $1.197 \mathrm{~mm}$ ), respectively. The mean difference between M-IMT and B-IMT (M-IMT minus B-IMT) and its SD was $0.011 \pm 0.091$ $\mathrm{mm}(95 \% \mathrm{CI}-0.167 \mathrm{~mm}$ to $0.188 \mathrm{~mm}$ ) (Fig. 1). ICC and CCC were 0.802 and 0.801 , respectively. Pearson (r) was 0.808 in the linear regression analysis $(\mathrm{y}=$ $0.906 x+0.073$; Fig. 2). Using this linear regression model, B-IMT and M-IMT were calculated as identical at $\mathrm{IMT}=0.779 \mathrm{~mm}$.

\section{DISCUSSION}

Agreement between the two methods was acceptable as evidenced by: 1 . limited deviation from the line of identity (CCC $\geq 0.8$ and almost identical to ICC); 2 . no important systematic difference between B-IMT and M-IMT (mean difference close to 0 and ICC almost identical to r); and 3. an acceptable overall correlation (ICC $\geq 0.8$ and $95 \% \mathrm{CI}$ of differences).

The measurement of the combined thickness of the intima and media (the intima-media thickness) of arteries and of the CCA in particular is widely applied. IMT of the common carotid artery has been used in populationbased epidemiologic studies (Burke et al. 1995; Gariepy

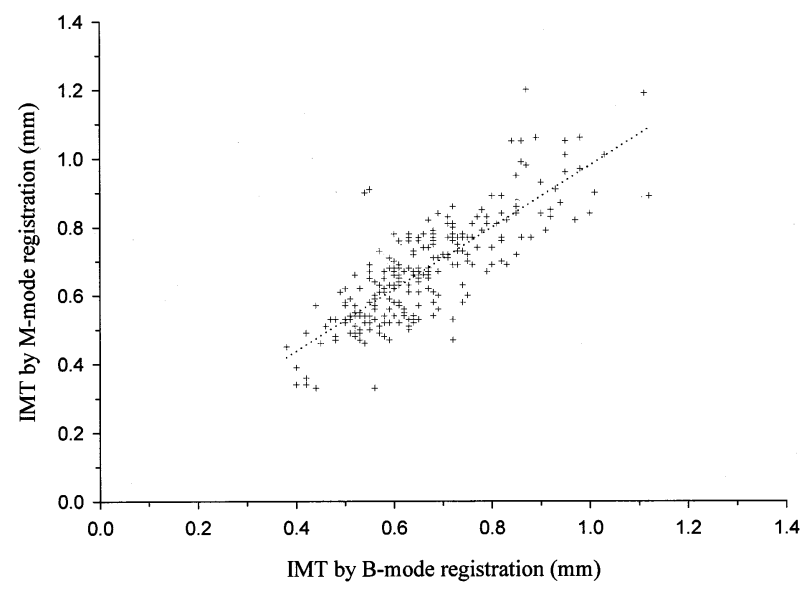

Fig. 2. Regression line of relation between M-IMT and B-IMT. M-IMT and B-IMT = intima-media thickness measured with M-mode and with B-mode, respectively.

et al. 1995; Grobbee and Bots 1994; Salonen and Salonen 1991), and is advocated and used as intermediate endpoint in clinical trials for the assessment of the middle- and long-term effects of treatment on progression or regression of atherosclerosis (Blankenhorn et al. 1993; Bond and Mercuri 1995; Borhani et al. 1986; Crouse et al. 1995; De Groot et al. 1995; Furberg et al. 1994; Mercuri et al. 1996; Westendorp et al. 1999). Local IMT, as a surrogate for wall thickness, is also required to assess arterial wall properties (e.g., the Young's modulus) (Joannides et al. 1997).

The large majority of studies on IMT used B-mode. Should B-mode be used in clinical practice rather than M-mode? The B-mode and M-mode methods both have their own advantages and disadvantages. B-IMT is the average IMT along a continuous arterial segment, and M-IMT measures only the IMT at one discrete position. As a consequence, differences between the two methods in the present study can, at least in part, be due to inhomogeneities of the arterial wall. The B-mode analysis is complicated by the speckle pattern and preprocessing of the video images (Easton et al. 1994). Averaging will reduce the influence of speckle on IMT measurements (Hoeks et al. 1997). The B-mode off-line analysis was shown to be more complex and time-consuming than the M-mode off-line analysis if no automated computerized calculation program is available.

In conclusion, there is no important systematic difference between B-IMT and M-IMT. There is acceptable agreement between the two methods. At values of B-IMT $<0.779 \mathrm{~mm}$ M-IMT tended to be higher and at values of B-IMT $>0.779 \mathrm{~mm}$ it tended to be lower, but this deviation from the line of identity is small and acceptable. 
Acknowledgements - The study was supported by the Cardiovascular Research Institute Maastricht (CARIM), Maastricht, The Netherlands. The expert technical assistance of J. Willigers and Mrs H. van Essen is gratefully acknowledged.

\section{REFERENCES}

Bland MJ, Altman DG. Statistical methods for assessing agreement between two methods of clinical measurement. The Lancet 1986; 1:307-310.

Blankenhorn DH, Selzer RH, Crawford DW, et al. Beneficial effects of colestipol-niacin therapy on the common carotid artery. Two and four year reduction of intima media thickness measured by ultrasound. Circulation 1993;88:20-28.

Bond MG, Ball M. Assessment of ultrasound B-mode imaging for detection and quantification of atherosclerotic lesions in arteries of animals (NHLBI No1-HV-12916). Bethesda, MD: National Heart, Lung, and Blood Institute 1986.

Bond MG, Mercuri M. Potential modification of plaque behavior through the European lacidipine study on atherosclerosis. J Cardiovasc Pharmacol 1995; 25(Suppl. 3):S11-S16.

Borhani NO, Mercuri M, Borhani PA, et al. Final outcome results of the multicenter isradipine diuretic atherosclerosis study (MIDAS). A randomized controlled trial. JAMA 1986;276:785-791.

Burke GL, Evans GW, Riley WA, et al. Arterial wall thickness is associated with prevalent cardiovascular disease in middle-aged adults. The atherosclerosis risk in communities (ARIC) study. Stroke 1995;26:386-391.

Crouse III Jr, Thompson CJ. An evaluation of methods for imaging and quantifying coronary and carotid lumen stenosis and atherosclerosis. Circulation 1993;87(Suppl. 2):17-33.

Crouse III Jr, Byington RP, Bond MG, et al. Pravastatin, lipids, and atherosclerosis in the carotid arteries (PLAC-II). Am J Cardiol 1995; 75:455-459.

De Groot E, Jukema JW, van Boven AJ, et al. Effects of pravastatin on progression and regression of coronary atherosclerosis and vessel wall changes in carotid and femoral arteries: A report from the Regression Growth Evaluation Statin Study. Am J Cardiol 1995; 76:40C-46C

Deyo RA, Diehr P, Patrick DL. Reproducibility and responsiveness of health status measures. Contr Clin Trials 1991;12:142-158.

Easton JD, Hennerici MG, Steinke W, et al. Accuracy of high-resolution ultrasound imaging for quantitative assessment of early carotid atherosclerosis. Cerebrovasc Dis 1994;4:109-113.

Furberg CD, Adams HP Jr, Applegate WB, et al. Coronary heart disease/myocardial infarction: Effect of lovastatin on early carotid atherosclerosis and cardiovascular events. Circulation 1994;90: $1679-1687$.

Gariepy J, Simon A, Massonneau M, et al. Wall thickening of carotid and femoral arteries in male subjects with isolated hypercholesterolemia. Atherosclerosis 1995;113:141-151.

Girerd X, Mourad JJ, Acar C, et al. Noninvasive measurement of medium-sized artery intima-media thickness in humans: In vitro validation. J Vasc Res 1994;31:114-120.

Grobbee DE, Bots ML. Carotid artery intima-media thickness as an indicator of generalized atherosclerosis. J Intern Med 1994;236: 567-573.

Hoeks APG, Willekes C, Boutouyrie P, et al. Automated detection of local artery wall thickness based on M-line processing. Ultrasound Med Biol 1997;23:1017-1023.

Intaglietta M, Tompkins WR. Microvascular measurements by video image shearing and splitting. Microvasc Res 1973;5:309-312.

Joannides R, Richard V, Haefeli WE, et al. Role of nitric oxide in the regulation of the mechanical properties of peripheral conduit arteries in humans. Hypertension 1997;30:1465-1470.
Kanters SDJM, Elgersma OEH, Banga JD, van Leewen MS, Algra A. Reproducibility of measurements of intima-media thickness and distensibility in the common carotid artery. Eur J Endovasc Surg 1998;16:28-35.

Lin LI. A concordance correlation coefficient to evaluate reproducibility. Biometrics 1989;45:255-268.

Mercuri M, Bond MG, Sirtori CR, et al. Pravastatin reduces carotid intima-media thickness progression in an asymptomatic hypercholesterolemic mediterranean population: The carotid atherosclerosis italian ultrasound study. Am J Med 1996;101:627-634.

Mountauban van Swijndregt AD, De Lange EE,De Groot E, Ackerstaff RG. An in vivo evaluation of the reproducibility of intima-media thickness measurements of the carotid artery segments using Bmode ultrasound. Ultrasound Med Biol 1999;25(3):323-330.

Persson J, Formgren J, Israelsson B, Berglund G. Ultrasound-determined intima-media thickness and atherosclerosis. Direct and indirect validation. Arterioscler Thromb 1994;14:261-264.

Pignoli P, Tremoli E, Poli A, Oreste P, Paoletti R. Intima plus medial thickness of the arterial wall: A direct measurement with ultrasound imaging. Circulation 1986;74:1399-1406.

Probstfield J, Margitic SE, Byington RP, Espeland MA, Furberg CD. Results of the primary outcome measure and clinical events from the Asymptomatic Carotid Artery Progression Study. Am J Cardiol 1995;76:47C-53C.

Roman MJ, Pini R, Pickering TG, Devereux RB. Non-invasive measurements of arterial compliance in hypertensive compared with normotensive adults. J Hypertens 1992;10(suppl. 6):S115-S118.

Salonen JT, Salonen R. Ultrasonographically assessed carotid morphology and the risk of coronary heart disease. Arterioscl Thromb 1991;11:1245-1249.

Smilde TJ, Wollersheim H, Van Langen H, Stalenhoef AF. Reproducibility of ultrasonographic measurements of different carotid and femoral artery segments in healthy subjects and in patients with increased intima-media thickness. Clin Sci Colch 1997;93:317324.

Stary HC, Blankenhorn DH, Chandler B, et al. A definition of the intima of human arteries and of its atherocslerosis-prone regions. Arterioscler Thromb 1992;12:120-134.

Stensland-Bugge E, Bonaa KH, Joakimsen O. Reproducibility of ultrasonographically determined intima-media thickness is dependent on arterial wall thickness. The Tromsö study. Stroke 1997;28: 1972-1980.

Tang R, Hennig M, Thomasson B, et al. Baseline reproducibility of B-mode ultrasonic measurement of carotid intima-media thickness: The European Lacipidine Study on Atherosclerosis. J Hypertens 2000;18:197-201.

Van der Heijden-Spek JJ, Staessen JA, Fagard RH, et al. The effect of age on brachial artery wall properties differs from the aorta and is gender dependent: A population study. Hypertension 2000;35:637642 .

Wendelhag I, Gustavsson T, Suurkula M, Berglund G, Wikstrand J. Ultrasound measurement of wall thickness in the carotid artery: Fundamental principles and description of a computerized analysing system. Clin Physiol 1991;11:565-577.

Westendorp ICD, In't Veld BA, Bots ML, et al. Hormone replacement therapy and intima-media thickness of the common carotid artery. The Rotterdam study. Stroke 1999;30:2562-2567.

Willekes C, Brands PJ, Willigers JM, Hoeks AP, Reneman RS. Assessment of local differences in intima-media thickness in the human carotid artery. J Vasc Res 1999;36:222-228.

Wong M, Edelstein J, Wollman J, Bond MG. Ultrasonic-pathological comparison of the human arterial wall: Verification of intima-media thickness. Arterioscler Thromb 1993;13:482-486. 